\title{
Increasing response rates and reducing bias: Learnings from the Smart Energy Research Lab pilot study
}

\author{
Ellen Webborn*a, Eoghan McKenna ${ }^{a}$, Simon Elamª ${ }^{a}$ Ben Anderson ${ }^{b}$, Adam Cooper $^{c}$, Tadj Oreszczyn ${ }^{a}$ \\ *e.webborn@ucl.ac.uk (corresponding author) \\ ${ }^{a}$ UCL Energy Institute, 14 Upper Woburn Place, University College London, WC1H ONN, UK \\ ${ }^{b}$ Faculty of Engineering and Physical Sciences, University of Southampton, Southampton, UK \\ ${ }^{c}$ Department of Science, Technology, Engineering and Public Policy, Shropshire House, Capper \\ Street, London WC1E 6JA, UK
}

\section{Highlights:}

- We test recruitment strategies to improve response to a smart energy meter study

- A conditional monetary incentive increases response and reduces sample bias

- A push-to-web approach reduces response but significantly increases online sign up

- Multiple reminders are useful but a $4^{\text {th }}$ mailing is unlikely to be cost-effective

- Motivational headlines and message structure impact response rates

\begin{abstract}
Obtaining high-resolution energy consumption data from a large, representative sample of homes is critical for research, but low response rates, sample bias and high recruitment costs form substantial barriers. The wide-spread installation of smart meters offers a novel route to access such data, but in countries like Great Britain (GB) consent is required from each household; a real barrier to large-scale sampling. In this paper we show how certain study design choices can impact the response rate and sample bias in energy studies requesting access to half-hourly smart meter data and (optional) survey completion. We used a randomised control trial (RCT) with a $3 \times 2 \times 2$ factorial design to test incentives, message content/structure and a 'push-to-web' approach in a large-scale pilot for the future $10,000+$ GB sample. Up to 4 mailings were sent to 18,000 addresses, recruiting 1711 participants $(9.5 \%$ response rate) from England and Wales. Our results and recommendations can be used to help future energy studies to achieve greater response rates and improved representation. UK-based researchers can apply to use our longitudinal smart meter and contextual datasets.
\end{abstract}

Keywords: energy survey, incentive, push-to-web, reminder, response rate, smart meter 


\section{INTRODUCTION}

To achieve net zero carbon emissions targets we need to better understand domestic energy consumption patterns and drivers, and anticipate changes going forward. For example, harnessing the potential flexibility of demand response will be key for supporting system operation [1]. Identifying households in fuel poverty or at risk of missing out on technological advancements or green policy incentives will be vital for transitioning to net zero both successfully and fairly [2]. Managing increases and time shifts in energy demand from the electrification of heat and transport will become increasingly important as electrification becomes more mainstream [3]. Such challenges call for a strong, nationally-representative empirical evidence base of high-resolution energy, building and occupant data [4-6].

Since the timing of consumption is crucial to the operation of a future $100 \%$ renewable electricity system [7-9], half hourly (or finer) smart meter data at scale from a large-N representative national sample will provide a significant uplift in energy research capability [4,5]. Anonymised (un-linkable) consumption data has limited value compared to rich, contextualised data that can provide co-variates to help explain patterns, understand drivers and assess the potential influence of policy, technologies or interventions [10].

In GB the prevalence of gas for cooking, hot water and space heating alongside electricity means that energy consumption research requires both gas and electricity energy inputs as well as suitable contextual data. However, access to such data is neither straightforward nor cheap. One option would be to recruit a household sample and install bespoke energy consumption monitors. Whilst this has been done in a number of studies (e.g. $[11,12])$, it has proven expensive and, in the case of gas consumption, technically difficult.

Clearly an attractive alternative is to make use of already-installed gas and electricity smart meters which collect at least half-hourly consumption data and for which a robust data communication system already exists for billing purposes. In GB smart meter data is owned by the consumer and governed by both GDPR and the Smart Energy Code (SEC); data access requires informed consent from each household [13]. Hence consumers must understand who is collecting their data and how it will be used, and trust that their privacy will be protected. Recruiting participants for any smart meter study therefore requires providing information that is both brief and easily understood, yet sufficient for an informed decision. The tasks of reading the information, returning a consent form, and perhaps completing a survey are non-trivial and well-known sources of response bias [14,15].

The purpose of this paper is to report an experiment designed to test recruitment methods to inform further participant recruitment to the Smart Energy Research Laboratory (SERL) 10,000+ observatory sample of GB-representative smart-metered households [16]. We tested strategies to reduce nonresponse and sample bias when asking participants for consent to access and link their smart meter data and to (optionally) complete a survey about their household and dwelling. Specifically, we required consent to access half-hourly electricity and gas import, and electricity export data ${ }^{1}$, as well tariff information stored on the meter, and consent to link these with other data sources such as Energy Performance Certificate (EPC) (a surveyed measure of the building's energy efficiency) and local weather data. Energy data collection continues over multiple years, stored indefinitely and made

\footnotetext{
${ }^{1}$ Electricity export data is available for households with micro-generation e.g. solar photovoltaics (PV). All smart meter data is collected via the DCC Gateway (see Section Error! Reference source not found.).
} 
available to researchers in a secure environment under strict conditions ${ }^{2}$. This is very different to survey studies such as $[17,18]$ for which consent to access energy data was encouraged but optional.

Here we report a brief overview of known and applicable recruitment methods, the results of the experiment, and make recommendations for improving response to postal recruitment for energy studies. In doing so the study makes the following empirically-novel contributions [19] to energy social science. First, our study is only the second (of which we are aware) to rigorously test a range of motivational strategies for participation in an energy study. Second, no other energy study has tested the effects of a push-to-web approach on response method (online or postal). Finally, we analyse the impact of tests not only on response rates but on response bias using Index of Multiple Deprivation (IMD) quintiles.

\section{DESIGNING A LARGE-SCALE HOUSEHOLD SMART METER STUDY}

Best practice in research design recommends establishing the research questions or hypotheses in advance and calculating the sample size necessary to detect the experimental effect(s) of interest $[19,20]$. In general, statistical power increases with study size; larger studies allow for greater precision in the results. Unfortunately, in this regard energy research lags behind areas such as health, where rigorous study design has long been a pre-requisite. A review of energy intervention studies found that many suffered from non-experimental designs, low sample sizes, no proper control group, no follow-up or very short time frames and/or self-selected participants [21]. Obstacles may include the costs and time involved in installing monitoring equipment or conducting face-to-face surveys and follow-ups. Such issues often reduce the value of a study by limiting the conclusions that can be drawn from small samples and, frequently, the scope for generalising the results beyond a self-selected sample. In contrast, smart meter data can be collected remotely from potentially millions of homes with no need for expensive technical installations and, when combined with a scientifically rigorous sample and study design, can provide a data resource to support substantially more precise results and robust conclusions. However, the target population must be carefully defined in the context of the research questions and objectives [21]. Even a meticulously-designed sampling procedure will suffer response bias which needs to be minimised through good practice and accounted for in reporting [22]. While participant sample size is often reported as the main indicator of a study's reliability/generalisability, response bias is a well-known issue that may be addressed, in part, by study design.

\subsection{WILLINGNESS TO SHARE ENERGY DATA}

Although there have been a small number of studies of the factors affecting consent for linkage to administrative data $[23,24]$, consumer willingness to share their smart meter data for research is not yet well understood. A recent UK consumer survey suggested that half-hourly energy consumption was considered less sensitive than other types of personal data such as financial and medical records, contact details, photos and videos, social media activity and location data [25].

Previous energy studies have reported a range of response rates when asking for energy consumption data. Some studies offered personalised advice on how to save energy, with response rates from 5$31 \%$ [26-28]. Feedback studies give an indication of consumer willingness to share energy data with researchers, but our study is different in two key ways. Firstly, feedback trials offer consumers

\footnotetext{
${ }^{2}$ For more information about the project and how to access data, see $[16,55]$.
} 
something in return for their data (beyond a one-off token incentive); they can learn about their energy consumption and potentially save money. Secondly, the messaging focus is likely to be on the study aims and benefits to participants rather than on data sharing and linking. Data is often accessed via the supplier who already has consent, and the data will not usually be linked with other sources or shared with other researchers.

The most similar study in the literature tested strategies to improve response to an energy study, optionally requesting access to energy data at the end [18]. The survey response rate was $10.1 \%$, of whom $60.4 \%$ (6.1\% overall) gave access to both energy data and meter installation date, $12.4 \%$ (1.3\% overall) consented to energy metering data only and $2.5 \%$ ( $0.3 \%$ overall) shared installation date only. Participant willingness to share personal data with anonymous recipients was tested in experimental studies in Germany [29]. No preference was detected for sharing less data with multiple groups versus more data with one group, implying data linkage was not seen as a particular issue ${ }^{3}$. People preferred not to share their data with "too many" unknown recipients, which could be relevant for researchers requesting access for data on behalf of a wider research community.

\subsection{MOTIVATIONAL STRATEGIES TO INCREASE AND WIDEN PARTICIPATION}

To become a participant in any study, invited recipients need sufficient motivation to respond and many (non-energy) studies have tested the effects of using motivational strategies such as monetary incentives, use of images, survey lengths and personalised feedback (for a review see [30]). Although energy studies have used motivational strategies to increase participation (such as follow-up contact/reminders [31], a prize draw [32,33], or retail vouchers [34]) few have robustly tested their relative effectiveness in the energy domain, which may well be different to other subject areas [18]. In this section we review the use of material incentives and reminders. We did not find studies testing different motivational messaging and invitation structure within the energy domain.

\subsubsection{Material incentives}

Material incentives can be monetary (e.g. a voucher or entry into a prize draw for money) or nonmonetary/gift-based (e.g. a small item like a pen or a prize to be won such as a car). Incentives conditional on a participant's actions, such as signing up to a trial or completing a survey ('conditional incentives') are a common form of extrinsic motivation, i.e. motivating a behaviour by offering an external reward [35]. Unconditional incentives provided upfront as a way to foster goodwill or a sense of obligation are forms of intrinsic motivation.

Research outside of the energy domain suggests that monetary incentives are generally more successful than non-monetary incentives [36-38] and unconditional (upfront) incentives tend to be more successful than conditional incentives $[39,40]$. However, the effects of incentives to motivate participation in health research or personal face-to-face interviews do not necessarily transfer to energy studies and requests to access energy data.

Material incentives have been used in energy research to boost response rates. [32] achieved a $20 \%$ response rate using a lottery with four monetary prizes (approximately 140 euros). [33] achieved a $19 \%$ response rate offering participants the chance to win $\$ 500$ dollars for their chosen charity. $\$ 10$ Amazon vouchers were offered to US participants recruited over 6 hours through Craigslist, recruiting 505 participants for a survey about perceptions of energy consumption and savings [34]. [18] performed a randomised control trial with an energy survey to test a non-monetary unconditional

\footnotetext{
${ }^{3}$ However, the personal data was not energy data and the authors note that linkage did not necessarily increase the value of the data.
} 
incentive (fridge magnet) and a conditional monetary incentive (entry into an AU\$200 retail gift prize draw); neither had a statistically significant impact.

\subsubsection{Reminders}

Reminders are useful for recipients who may have missed, ignored, forgotten or failed to complete the initial request [41-43]. Reminders also have the potential to signal the importance and legitimacy of a study, and the value of the recipient's participation to the researchers [44].

A Swedish energy consumption feedback device study [45] offering cinema tickets for participation achieved response rates in different cities of $35 \%$ and $54 \%$ (with two reminders), $46 \%$ (one reminder) and $41 \%$ response rate (no reminders). A UK face-to-face energy study included a follow-up paperbased appliance ownership survey and reminder for the original participants, of whom $36.6 \%$ took part. An additional reminder was found to significantly increase response (from $34 \%$ to $44 \%$ ) to Wave 8 of the Understanding Society survey [46]. Although a reminder postcard did not significantly increase response in [18], a combination of an envelope message with the reminder did show a significant benefit.

\subsection{SURVEY APPROACHES}

Choice of survey method (face-to-face, postal, telephone etc.) affects response rates, costs, sample bias and data quality and must therefore be considered carefully. [47] advises caution when attempting to compare response rates from different types of survey delivery, and finds examples of both high and low response rates across all methods. Face-to-face delivery allows an interviewer to ensure a participant understands the questions and can double-check responses but may suffer from illegible handwriting and (depending on the approach used) may have limited question routing to reduce respondent burden. Online surveys allow for automatic response checking and question routing and avoids handwriting issues. A push-to-web approach (also known as 'web first' and 'web push') initially invites participants to take part online, potentially with incentives for online response, but offers a postal sign-up option later to non-responders [48]. Push-to-web approaches have been found to boost online response and be more cost-effective than traditional recruitment methods $[46,49]$. In a US study, offering an online option decreased response compared to providing postalonly but an online option followed later by a postal option ("web + mail" design) with a pre-paid \$5 incentive achieved response rates of around $50 \%$, to which two-thirds responded online [48]. Offering online and postal response to undergraduates in the US did not increase response rates compared to offering postal-only response, "even among a highly Internet-literate population" [50].

To date we are unaware of any tests on the impact of push-to-web approaches for energy studies. Some have offered both online and postal response options, such as [18], which achieved a $10.1 \%$ response rate (1861 participants), of which approximately $23 \%$ responded online.

\section{THE SERL EXPERIMENTAL PILOT STUDY}

Households known to have a smart meter (see Section 4.2 for details) were randomly selected for the study and only property address was known (no names, email or telephone contact details). Due to the high cost of face-to-face recruitment, participants were sent an invitation by post with up to three reminders to increase response and potentially reduce bias [14].

An experimental design was employed following best-practice guidelines [42] to scientifically test four types of motivational strategy (material incentives, push-to-web, message content/structure and 
reminders) on response rates and sample representativeness. We tested three incentive conditions: an unconditional incentive (room thermometer), a conditional $£ 5$ voucher, and no incentive. We chose a room thermometer (shown in Appendix 10.3) as it was energy related, enabled motivational messaging and partner logos, and was cheap to post. We hypothesised that this may encourage signup via the norm of reciprocity [51], by which people reciprocate positive gestures. A f5 'Love2Shop' voucher [52], redeemable at over 100 retailers $^{4}$, was offered conditional on participation. Although cash incentives have shown to be more effective when they are unconditional rather than conditional [39], our low expected response rate (estimated a priori to be within 5-20\%) and high recruitment goal (ultimately around 10,000 participants) meant unconditional cash incentives would be too expensive. Due to the lower costs and data quality benefits of online response, we offered online participation in all mailings to all treatment groups. A control group was also offered postal participation in mailings 1 and 3 while the push-to-web treatment group was only sent the postal response forms in mailing 3 .

Our main research questions are:

1. What are the effects of the incentives on response rates?

2. What are the effects of the push-to-web approach on response rates and signup method?

3. What are the effects of using different messaging/structure combinations on response rates?

4. What are the effects of sending a $4^{\text {th }}$ mailing (i.e. $3^{\text {rd }}$ reminder) on response rates?

Based in part on the results of previous studies, we hypothesise that:

a) the material incentives will significantly increase response rates compared to the control group

b) the push-to-web approach will significantly increase online participation compared to the control group

c) households in areas of greater deprivation are more likely to respond to a monetary incentive (due to placing a higher value on the incentive)

d) households in areas of greater deprivation are less likely to respond to a push-to-web approach (due to less internet access).

\section{METHODS}

\subsection{INVITATIONS TO PARTICIPATE}

Our recruitment approach involved writing to randomly-selected addresses up to 4 times to invite them to participate in SERL. Mailings were sent 13 days apart ${ }^{5}$ to give participants time to respond and for the letters to arrive on different days of the week to increase the chance of response. All mailings were sent in an A5 envelope with three project partner logos above the tagline "University research for public good". The clear panel on the envelope showed the address and "Dear Sir/Madam" at the start of the invitation (or reminder) letter. A room thermometer was included in the first mailing for households in the incentive strategy treatment group 1 (see Appendix 10.3). Recipients in Wales received all documents in both English and Welsh and the online participant portal had a Welsh language version.

\footnotetext{
${ }^{4}$ An unconditional f10 Love2Shop voucher was successfully trialled in [46] (designed to boost online response).

${ }^{5}$ The exception was mailing 4 which was sent 14 days after mailing 3 due to a postal strike. Mailings were expected to take 1-3 working days to arrive.
} 


\subsection{SAMPLE SELECTION PROCEDURE}

The GB smart meter rollout is currently led by energy suppliers and customers are encouraged but not obliged to have a smart meter installed. Data is stored on the meter and accessible to approved parties via the DCC Gateway; a secure messaging service which communicates rather than storing the data. Non-retailers, such as a university research team, can use the DCC Gateway to retrieve data if they have demonstrated compliance with the Smart Energy Code which requires opt-in consent from the consumer [53]. It is currently only possible to access data from GB households with a DCC-enrolled smart meter; SMETS2 or upgraded SMETS1 smart meters which store half-hourly energy readings for up to 13 months.

Since the GB smart meter rollout was not spatially homogenous ${ }^{6}$ we were forced to select the sample to be representative of seven regions in England and Wales where smart meter coverage was generally highest ( $2-3 \%$ of the addresses we queried using the DCC). The first step in sample recruitment was to randomly select 900,000 UPRNs (Unique Property Reference Numbers) from Ordnance Survey's AddressBase $^{7}$ database for our seven selected regions and use the DCC to determine whether a DCCcompatible meter existed at each address ${ }^{8}$. This returned 24,650 viable addresses $(2.7 \%$ of the addresses queried).

Based on their experience with other research studies fieldwork agency Ipsos MORI estimated a 5$20 \%$ response rate. Our goal was to recruit 1000-4000 participants in the pilot study, and so based on the budget and these estimates a sample size of 18,000 of addresses was chosen for the study.

Each LSOA (Local-layer Super Output Area) in GB has an index of multiple deprivation (IMD); an areabased, ranked measure of deprivation based on factors such as income, employment and crime at the local level (separate for England, Scotland and Wales). The most deprived LSOAs have IMD quintile 1; the most affluent IMD quintile 5. Given that local measures of deprivation are well known to correlate with response rates, we applied a stratified random selection approach to our initial address sample; selecting 18,000 such that the proportion in each IMD quintile and region were representative of the proportion of the population. Note that the percentage of households in each IMD quintile varies significantly between regions, as shown in Figure 1 . This means that we will need to consider IMD quintile effect when assessing regional response rates.

\footnotetext{
${ }^{6}$ We found less than $0.5 \%$ of dwellings in the North of England and Scotland had operational DCC-compliant smart meters in June 2019.

${ }^{7}$ Filtering was first applied to the Address Base data to remove addresses with an organisation name, were not 'in use', or did not have an 'approved' delivery point address or geographical (local authority) address.

${ }^{8}$ Specifically, we were checking whether an ESME (Electricity Smart Metering Equipment) existed and had a 'commissioned' status. This information did not require consent from the households.
} 


\begin{tabular}{|c|c|c|c|c|c|}
\hline $\begin{array}{l}\text { West Midlands } \\
2356 \text { total }\end{array}$ & $3.7 \%$ & $2.5 \%$ & $2.6 \%$ & $2.3 \%$ & $1.9 \%$ \\
\hline $\begin{array}{c}\text { Wales } \\
1471 \text { total }\end{array}$ & $1.6 \%$ & $1.7 \%$ & $1.8 \%$ & $1.8 \%$ & $1.5 \%$ \\
\hline $\begin{array}{l}\text { South West } \\
2443 \text { total }\end{array}$ & $1.6 \%$ & $2.8 \%$ & $3.6 \%$ & $3.2 \%$ & $2.5 \%$ \\
\hline $\begin{array}{c}\text { South East } \\
3674 \text { total }\end{array}$ & $1.6 \%$ & $3.2 \%$ & $4.1 \%$ & $4.9 \%$ & $6.7 \%$ \\
\hline $\begin{array}{r}\text { Greater London } \\
3580 \text { total }\end{array}$ & $4.6 \%$ & $6.3 \%$ & $4.2 \%$ & $3 \%$ & $1.8 \%$ \\
\hline $\begin{array}{l}\text { East Of England } \\
2506 \text { total }\end{array}$ & $1.5 \%$ & $2.6 \%$ & $3.4 \%$ & $3.2 \%$ & $3.2 \%$ \\
\hline \multirow[t]{2}{*}{$\begin{array}{l}\text { East Midlands } \\
1970 \text { total }\end{array}$} & $2.1 \%$ & $2.3 \%$ & $2.1 \%$ & $2.4 \%$ & $2.1 \%$ \\
\hline & $\begin{array}{c}1 \\
2981 \text { total }\end{array}$ & $\begin{array}{c}2 \\
3838 \text { total }\end{array}$ & $\begin{array}{c}3 \\
3917 \text { total } \\
\text { MD Quintile }\end{array}$ & $\begin{array}{c}4 \\
3734 \text { total }\end{array}$ & $\begin{array}{c}5 \\
3530 \text { total }\end{array}$ \\
\hline
\end{tabular}

Figure 1: Percentage of households invited for participation in each index of multiple deprivation (IMD) quintile and region, reflective of the full population.

\subsection{EXPERIMENTAL DESIGN}

We used a $3 \times 2 \times 2$ factorial design to test the recruitment strategies (Table 1 ), and randomly (and evenly) allocated the 18,000 chosen addresses to each of the 12 test cells (1500 per cell), such that the proportion in each IMD quintile and region was representative of the population (Figure 1).

Table 1: Summary of the randomised experiments

\section{RCT and description of strategy Randomly-assigned groups}

\section{Incentives}

RCT to test the effectiveness of two types of incentive:

- Unconditional token gift in mailing 1: room thermometer with messaging and project branding

- Conditional $f 5$ Love2Shop voucher following sign up

\section{Push-to-web}

$\mathrm{RCT}$ to test the impact on response and response method of reducing the number of opportunities to sign up by post. All four mailings offered online sign up, postal signup options depended on the treatment group.

\section{Message content}

RCT to test the impact of message structure on response. Two versions, see Table 2 for details.

\section{3 groups:}

- Treatment group 1 (unconditional thermometer)

- $\quad$ Treatment group 2 (conditional voucher)

- Control group (no incentive)

2 groups:

- Treatment group (push-toweb): postal signup available in mailing 3

- Control group: postal signup available in mailings 1 and 3

\section{2 groups:}

- $\quad$ Treatment group 1 (version 1)

- Treatment group 2 (version 2)

\subsection{MATERIALS}

\subsubsection{Cover letter and accompanying information}

The invitation letter and reminders for this study were designed based on the Tailored Design Method [42] and drew upon the experience of contracted research agency Ipsos MORI. The aims of the letters 
were to provide the information needed for participants to complete the consent form and survey and to address likely questions ${ }^{9}$. Our guiding principles for the design of the letters were:

- Simple and easy language, no unnecessary or complicating text

- Cover the key messages:
0 the importance of taking part
- reasons for taking part
- how to take part
$\circ$ the security of personal data.

Ipsos MORI has conducted several qualitative studies on the subject of smart meter data sharing and provided their expertise to help create the key messages to resonate with consumers. It is best practice to amend the wording of the invite in each subsequent mailing to increase the chances of addressing the motivations of different sample sub-groups [42]. We therefore used different headline messages in each reminder and alternated the message structure. We are unaware of any other energy studies to have tested messaging content in this way. Table 2 shows the four headline messages chosen to motivate potential participants to take part in the study and the two structures which alternated between mailings. The recipients were split randomly into treatment groups 1 and 2 , who received up to four mailings with the headlines and structures shown.

Table 2: Headlines and message structure for each mailing for each message content treatment group.

\begin{tabular}{|c|c|c|c|}
\hline Headline message & Structure & Group 1 & Group 2 \\
\hline $\begin{array}{l}\text { HELP TO MAKE OUR ENERGY FIT FOR } \\
\text { FUTURE GENERATIONS }\end{array}$ & $\begin{array}{l}\text { 1. Reasons for taking part } \\
\text { 2. Call to action }\end{array}$ & Mailing 1 & Mailing 4 \\
\hline $\begin{array}{l}\text { HELP THE UK TO BECOME MORE ENERGY } \\
\text { EFFICIENT }\end{array}$ & $\begin{array}{l}\text { 1. Call to action } \\
\text { 2. Reasons for taking part }\end{array}$ & Mailing 2 & Mailing 3 \\
\hline $\begin{array}{l}\text { HELP TO PROTECT THE ENVIRONMENT FOR } \\
\text { YOUR FAMILY AND FUTURE GENERATIONS }\end{array}$ & $\begin{array}{l}\text { 1. Reasons for taking part } \\
\text { 2. Call to action }\end{array}$ & Mailing 3 & Mailing 2 \\
\hline $\begin{array}{l}\text { HELP TO REDUCE FUTURE HOUSEHOLD } \\
\text { ENERGY BILLS }\end{array}$ & $\begin{array}{l}\text { 1. Call to action } \\
\text { 2. Reasons for taking part }\end{array}$ & Mailing 4 & Mailing 1 \\
\hline
\end{tabular}

The cover letter invited or reminded participants to take part, explaining why and how they could sign up, how the data would be used, and a set of FAQs, and an information sheet was also provided. Examples are included in Appendix 10.2.

\subsubsection{Consent form}

Mailing 1 and/or 3 (treatment group-dependent) included a consent form and survey with a pre-paid stamped addressed envelope for postal signup (copy in [54] documentation). The consent form and corresponding participant information sheet were checked and approved by the University College London (UCL) ethics committee. Unlike in other studies such as [18], the consent to share and link smart meter data was required to be a SERL participant; the survey was optional.

\subsubsection{Survey}

Survey questions (copy in [54] documentation) were collated by SERL consortium partners as being reliable, robust and most useful to research. Where possible they were harmonised with existing surveys such as the UK Census and the English Housing Survey to enable sample comparison. The online and postal surveys had identical questions; the online survey allowed for automatic question

\footnotetext{
${ }^{9} \mathrm{~A}$ helpline and email address were also provided to assist participants if needed.
} 
routing and error checking and was designed for use on a computer, mobile or tablet. The survey comprised four sections:
A. About your energy use and heating (16 questions)
B. About your accommodation (10 questions)
C. About your household (6 questions)
D. About you (4 questions).

\subsubsection{Cognitive testing}

Cognitive testing was carried out using close-to-final drafts of the participant materials (invitation letter, information sheet, consent form, paper survey). Ten smart meter owners spanning a range of demographics (age, gender, life stage) were interviewed and asked to 'sign up' (half online, half by post). The exercise took approximately 60-90 minutes.

The mailings were well received in the cognitive tests; key messaging was clear, objectives and signup requirements understood by all, content was deemed credible and trustworthy, and the reasons for taking part resonated with the participants. They were not overly concerned about the prospect of having to provide consent, and half were interested in taking part, albeit in an artificial setting. Some would have preferred more information, others less. Based on their feedback some survey questions were reworded to avoid confusion.

\subsection{DATA ANALYSIS AND ACCESS}

For information on how to access the SERL datasets see [55]. Code performed for this paper is available on GitHub ${ }^{10}$ and was performed using R 4.0.3 [56] and R packages broom [57], car [58], data.table [59], flextable [60], ggplot2 [61], RColorBrewer [62], and stringr [63]. Unfortunately the research data is confidential and therefore cannot be made available.

\section{RESULTS}

This pilot study recruited 1711 participants; ${ }^{11}$ a $9.5 \%$ response rate $(95 \% \mathrm{Cl}: 9.1-9.9 \%)$. A further 256 households returned their postal forms but did not successfully provide consent (e.g. form left blank or not all consent boxes ticked/no signature). 1671 (97.7\%) of participants started the (optional but encouraged) SERL survey; 76.7\% of participants answered in full. 837 (50.1\%) completed the survey online, 827 (49.5\%) on paper and $46(2.8 \%)$ did both. On average participants took approximately 13 minutes to complete the online survey (excluding four outliers who completed over multiple days). Of those who signed up online, $55 \%$ used a computer, $18 \%$ used a smartphone and $16 \%$ used a tablet (for $11 \%$ the device type was unknown).

\subsection{OVERALL SAMPLE REPRESENTATIVENESS}

\subsubsection{Index of Multiple Deprivation (IMD)}

Table 3 shows response rate by IMD quintile (see Section 4.2 for IMD details) and we see a clear relationship between IMD and response rate. The higher the IMD quintile (the greater the affluence

\footnotetext{
${ }^{10}$ https://github.com/smartEnergyResearchLab/PilotStudyPaper

${ }^{11}$ Our a priori estimate was $900-3600$ participants (5-20\% response rate).
} 
of the area), the higher the response rate, with households in IMD quintile 5 being twice as likely to participate as those in IMD quintile 1.

Table 3: Participation by Index of Multiple Deprivation quintile

\begin{tabular}{r|rrrrr} 
IMD quintile & Starting N & Participants & Response Rate & Lower 95\% Cl & Upper 95\% Cl \\
$\mathbf{5}$ & 3530 & 452 & $12.80 \%$ & $11.70 \%$ & $13.91 \%$ \\
$\mathbf{4}$ & 3734 & 433 & $11.60 \%$ & $10.57 \%$ & $12.62 \%$ \\
$\mathbf{3}$ & 3917 & 347 & $8.86 \%$ & $7.97 \%$ & $9.75 \%$ \\
$\mathbf{2}$ & 3838 & 289 & $7.53 \%$ & $6.70 \%$ & $8.36 \%$ \\
$\mathbf{1}$ & 2981 & 190 & $6.37 \%$ & $5.50 \%$ & $7.25 \%$ \\
\hline All & 18000 & 1711 & $9.50 \%$ & $9.07 \%$ & $9.93 \%$
\end{tabular}

Table 9 in Appendix 10.2Error! Reference source not found. shows the results of a logistic regression model of participation controlling for IMD quintile, region and treatments. We find that IMD quintile is statistically significant $(p<0.05)$ when comparing with the base case IMD quintile 3.

\subsubsection{Regional response rates}

Regionally response rates varied between $8.0 \%$ and $11.6 \%$ (Table 4). The relatively high response rate in Wales may be because their envelopes were bulkier (and thus potentially more likely to be opened) from the duplication of the materials in Welsh, or because our translation efforts presented us as a more professional/committed organisation. It is likely that the variation in response rates between the other regions is due to an uneven split of IMD quintiles (Section 4.2), and our logistic regression model (Table 9, Appendix 10.2) supports this - only Wales has a statistically significant effect $(p<0.05)$ compared to the region with the median response rate; the South East.

Table 4: Participation by region ordered by response rate.

\begin{tabular}{r|rrrr|r} 
Region & Starting N & Participants & Response rate & Lower 95\% Cl & Upper 95\% Cl \\
Wales & 1471 & 171 & $11.62 \%$ & $9.99 \%$ & $13.26 \%$ \\
East of England & 2506 & 263 & $10.49 \%$ & $9.29 \%$ & $11.69 \%$ \\
South West & 2443 & 256 & $10.48 \%$ & $9.26 \%$ & $11.69 \%$ \\
South East & 3674 & 369 & $10.04 \%$ & $9.07 \%$ & $11.02 \%$ \\
West Midlands & 2356 & 198 & $8.40 \%$ & $7.28 \%$ & $9.52 \%$ \\
Greater London & 3580 & 296 & $8.27 \%$ & $7.37 \%$ & $9.17 \%$ \\
East Midlands & 1970 & 158 & $8.02 \%$ & $6.82 \%$ & $9.22 \%$ \\
\hline All & 18000 & 1711 & $9.50 \%$ & $9.07 \%$ & $9.93 \%$
\end{tabular}

\subsection{TREATMENT EFFECTS}

Logistic regression was performed to test whether any of the recruitment strategies had a significant effect on participation rates, controlling for IMD quintile and region (Table 5). Participation ( $0=$ no participation, 1 = participation) was the response (dependent) variable in the analysis. Explanatory variables (analysed separately) were: incentive (none, conditional $f 5$ voucher, unconditional room thermometer), content (versions 1 and 2), and push-to-web approach (True (1 postal response option) or False (2 postal response options)).

Response was increased significantly at the $p<0.05$ level by the conditional $f 5$ voucher $(14.7 \%, \mathrm{Cl}$ : 1$30 \%)$ and content version 1 (15.9\%, Cl: 5-28\%). The push-to-web approach decreased response by 11.2\% ( $\mathrm{Cl}: 2-20 \%$ ) however, online response compared to postal response was significantly higher for the push-to-web approach (see Section 5.2.2). 
Table 5: Results of the logistic regression analysis to test the effects of the treatments, controlling for region and IMD quintile (full table in Appendix 10.1). p-values $<0.05$ in bold.

\begin{tabular}{|c|c|c|c|c|c|c|}
\hline Category & Variable & $\begin{array}{r}\text { Coefficient } \\
(95 \% \mathrm{Cl})\end{array}$ & $\begin{array}{l}\text { Odds Ratio } \\
\text { (95\% Cl) }\end{array}$ & $\begin{array}{r}\text { Standard } \\
\text { error }\end{array}$ & Z value & P-value \\
\hline Incentive & Thermometer & $\begin{array}{r}0.066 \\
(-0.058,0.190)\end{array}$ & $\begin{array}{r}1.068 \\
(0.943,1.210)\end{array}$ & 0.063 & 1.042 & 0.298 \\
\hline Incentive & Voucher & $\begin{array}{r}0.137 \\
(0.014,0.260)\end{array}$ & $\begin{array}{r}1.147 \\
(1.014,1.296)\end{array}$ & 0.063 & 2.186 & 0.029 \\
\hline Push-to-web & TRUE & $\begin{array}{r}-0.119 \\
(-0.219,-0.019)\end{array}$ & $\begin{array}{r}0.888 \\
(0.803,0.981)\end{array}$ & 0.051 & -2.325 & 0.020 \\
\hline $\begin{array}{l}\text { Content } \\
\text { version }\end{array}$ & Version 1 & $\begin{array}{r}0.147 \\
(0.047,0.248)\end{array}$ & $\begin{array}{r}1.159 \\
(1.048,1.281)\end{array}$ & 0.051 & 2.883 & 0.004 \\
\hline
\end{tabular}

\subsubsection{Incentives}

The conditional $f 5$ voucher had a useful effect on sign-up to SERL, increasing participation by $14.7 \%$ (CI: $1-30 \%$ ) according to the logistic model, from $8.9 \%$ (no incentive) to $10.1 \%$. In contrast any effect of the unconditional thermometer was not statistically significant $(p=0.30)$. We hypothesised that households in lower IMD quintiles would be more likely to participate if offered a financial incentive, but our logistic regression model with interaction effects (Table 10, Appendix 10.1) did not find a significant interaction between IMD quintile and incentive.

\subsubsection{Push-to-web approach}

The push-to-web treatment reduced response by $11.2 \%$ ( $\mathrm{Cl}: 2-20 \%$ reduction, Table 5$)$. However, we are also interested in a) the effect of the push-to-web treatment on sign-up method (online or postal), since online is cheaper and the survey data is better quality due to automatic question skipping and response checks, and b) the effect on the number of survey responses. Table 6 shows the breakdown of response by sign-up method for the two treatment groups. Almost two-thirds of the push-to-web group responded online, compared to only around one-third of the control group. We hypothesised that households in lower IMD quintiles (areas of greater deprivation) would be less likely to prefer online signup, and therefore be less represented in the push-to-web response sample. However, testing interaction effects between IMD quintile and push-to-web treatment found no significant effect (Table 10, Appendix 10.1).

Table 6: Response rates and methods (online or by post) by push-to-web treatment group. Push-to-web respondents only received postal forms in mailing 3; the control group received them in mailings 1 and 3 . All mailings included an online signup option.

\begin{tabular}{|c|c|c|c|c|c|c|}
\hline \multirow[t]{2}{*}{ Treatment } & \multirow[t]{2}{*}{ Starting N } & \multirow[t]{2}{*}{ Participants } & \multirow[t]{2}{*}{$\begin{array}{r}\text { Response } \\
\text { rate }\end{array}$} & \multicolumn{3}{|c|}{$\begin{array}{c}\text { Sign-up method } \\
\text { (N, \% of participants by treatment) }\end{array}$} \\
\hline & & & & Online & Post & Both $^{12}$ \\
\hline \multirow[t]{2}{*}{ 1: Push-to-web } & 9000 & 810 & $9.0 \%$ & 521 & 256 & 33 \\
\hline & & & & $64.3 \%$ & $31.6 \%$ & $4.1 \%$ \\
\hline \multirow[t]{2}{*}{ 2: Control group } & 9000 & 901 & $10.0 \%$ & 318 & 562 & 21 \\
\hline & & & & $35.3 \%$ & $62.4 \%$ & $2.3 \%$ \\
\hline \multirow[t]{2}{*}{ All } & 18000 & 1711 & $9.5 \%$ & 839 & 818 & 54 \\
\hline & & & & $49.0 \%$ & $47.8 \%$ & $3.2 \%$ \\
\hline
\end{tabular}

\footnotetext{
12 In these cases, we retained the online survey responses.
} 
This disadvantage of online sign up was that 39 participants did not start the survey unlike all postal participants. However, of those who started the survey, online participants were more likely to complete all required questions, and data quality was higher due to response checking and automatic question skipping. Online sign up also required participants to tick all consent boxes to continue, whereas 256 households only partially completed the consent form before starting the survey, and so they could not become participants. 25 push-to-web households contacted the helpdesk to request postal sign-up materials after the first or second mailing, which they received in mailing 3.

\subsubsection{Message content}

Two mailing design treatments were tested that differed in the timing of each headline and message structure (Table 2). Treatment 1 increased response by $15.9 \%$ (Cl 5-28\%) compared to treatment 2 (Table 7). In the most important mailings $(1 \text { and } 3)^{13}$ group 1 received headlines relating to family/future generations with 'reasons for taking part' followed by the 'call to action'. It is not possible to attribute the effect on response to either the structure or headline messages, but we can say that either or both of using a message about future generations or presenting the reasons for participation first are beneficial in the key mailings.

Table 7: Effect of the mailing content treatments, $\mathrm{Cl}=$ confidence interval. See Table 9 for full model statistics.

\begin{tabular}{l|rrrrr} 
Content & Starting N & Participants & $\begin{array}{r}\text { Response } \\
\text { rate }(95 \% \mathrm{Cl})\end{array}$ & $\begin{array}{r}\text { Odds ratio } \\
(95 \% \mathrm{Cl})\end{array}$ & $p$-value \\
Treatment 1 & 9000 & 912 & $\begin{array}{r}10.1 \% \\
(9.5-10.8 \%)\end{array}$ & $\begin{array}{r}1.159 \\
(1.05-1.29)\end{array}$ & 0.004 \\
& & & $8.9 \%$ & - & - \\
Treatment 2 & 9000 & 799 & $(8.3-9.5 \%)$ & & \\
\hline
\end{tabular}

\subsubsection{Multiple reminders}

Table 8 shows the response to each mailing, all of which increased participation. We were interested in whether the $4^{\text {th }}$ mailing would be cost-effective in increasing response and/or reducing bias. Mailing 4 had a low response rate (1.3\%), increasing the total sample size by around $15 \%$ (from $8.3 \%$ to $9.5 \%$ ). Hence to be cost-effective a $4^{\text {th }}$ mailing would need to be over 6 times cheaper than the cost of mailings 1-3. The effect on representativeness (in terms of IMD quintile) of each successive mailing can be seen visually in Figure 2, and we see no substantial benefit of a fourth mailing on boosting response from the under-represented IMD quintiles.

Table 8: Participation by mailing number (sent approximately 2 weeks apart). Mailings 1 and/or 3 contained a postal response option (treatment dependent).

\begin{tabular}{r|rrrrrr} 
Mailing & $\begin{array}{r}\text { Starting } \\
N\end{array}$ & $\begin{array}{r}\text { Participants } \\
\text { per mailing }\end{array}$ & $\begin{array}{r}\text { Response rate } \\
\text { per mailing }\end{array}$ & $\begin{array}{r}\text { Cumulative } \\
\text { Response }\end{array}$ & $\begin{array}{r}\text { Percent of } \\
\text { recruits }\end{array}$ & $\begin{array}{r}\text { Increase in } \\
\text { recruits }\end{array}$ \\
\hline 1 & 18,000 & 608 & $3.4 \%$ & $3.4 \%$ & $35.5 \%$ & - \\
2 & 17,392 & 412 & $2.4 \%$ & $5.7 \%$ & $24.1 \%$ & $67.8 \%$ \\
3 & 16,980 & 470 & $2.8 \%$ & $8.3 \%$ & $27.5 \%$ & $46.1 \%$ \\
4 & 16,510 & 221 & $1.3 \%$ & $9.5 \%$ & $12.9 \%$ & $14.8 \%$ \\
\hline
\end{tabular}

\footnotetext{
${ }^{13}$ The first mailing is the most important as the information is new to participants, and the third mailing includes postal sign-up materials to all participants. These mailings had the highest response overall.
} 


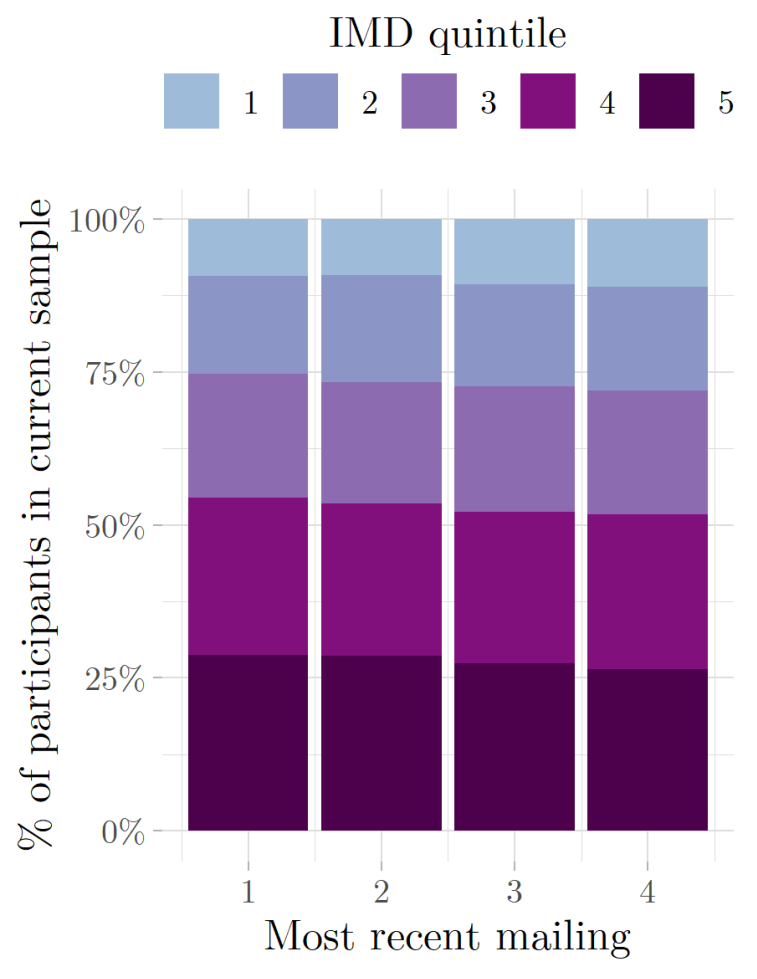

Figure 2: IMD quintile representation in the recruited sample after each successive mailing.

\section{DISCUSSION}

\subsection{SUMMARY OF KEY FINDINGS}

Our results illustrate the value of testing response rates with an initial pilot study, show the relative effectiveness of a range of recruitment strategies, and highlight the benefits of sample stratification by an area-based affluence metric (e.g. IMD quintile). We found that under the right conditions there is willingness among GB consumers to share half-hourly data for academic research.

Overall, we achieved a response rate of $9.5 \%$ (Table 3) which is comparable to the Australian study [18] in which $10.1 \%$ of households completed the survey and $7.4 \%$ consented to sharing energy data. Our response rate was lower than for national face-to-face surveys [22] and generally lower than energy feedback studies [26-28]. This is unsurprising since envelopes were not addressed to individuals and householders received no feedback (although some received an incentive).

In terms of recruitment strategies, the content/structure version had the greatest impact on response (a 15.9\% (CI: 5-28\%) increase in response rate), despite the only difference being the ordering of the mailings. We attribute this affect to the motivational messaging about family and future generations being in the most important mailings ( 1 and 3 ), and/or the potentially more effective structure to put the reasons for taking part before the call to action.

The conditional $f 5$ voucher increased response by $14.7 \%$ (Cl: 1-30\%) compared to no incentive. [18] reported that a prize draw conditional incentive was not effective, implying that a small chance of winning a larger amount may be a less effective extrinsic motivator than a guaranteed small amount. The unconditional thermometer incentive made no significant impact although it could only be sent 
in the first mailing and may have been missed. The incentives did not show a significant effect on sample representativeness.

The push-to-web approach decreased response by $11.2 \%$ (Cl: $2-20 \%$ ) but significantly increased online participation to a far greater extent, counter-balancing the depression in overall response given the study objectives (Table 6 ). Including a postal response option cost $~ 70 \%$ more per mailing than an online-only mailing, and processing an inbound postal response increased the cost by a further $\sim 50 \%$. Data fidelity was higher for those completing online as automatic checks and question skipping could be implemented. Those who started the survey online were more likely to finish it than those completing on paper, however, a small number of online participants did not click the link to start the survey after signing up. The push-to-web approach did not appear to disproportionately affect participation from any IMD quintile. Offering a choice of response options has previously been found to reduce participation, due to the additional effort required to weigh up the opportunity costs of each [50]. This was not the case in our study, although it is worth noting that envelopes with both response options were visibly bulkier, which may have enticed more people to open them. However, were this a major influence we would expect more of the control group to have responded online.

The fourth mailing increased the overall response rate from $8.3 \%$ to $9.5 \%$. To be cost-effective (compared to sending three mailings to a new address) a $4^{\text {th }}$ mailing would need to be less than $1 / 6^{\text {th }}$ of the cost of the three mailings. Since it does not appear to improve response bias, given our underrepresentation of households in areas of greater deprivation (lower IMD quintiles), our preference for future SERL recruitment is to over-sample from under-represented areas with fewer mailings rather than send a fourth mailing to all addresses.

\subsection{PRACTICAL IMPLICATIONS}

Our findings have practical implications for future studies requiring consumer consent to access energy data and/or survey responses. Cost-effective strategies to recruit a representative sample of the population are needed for such research, and we are able to suggest evidence-based study design choices.

To boost response rates, we recommend a conditional voucher (we used a $f 5$ redeemable at multiple retailers) and advise against a token (unconditional) gift. For similar studies we recommend designing invitation/reminder letters with the content and structure usage of treatment group 1 (Table 2) which focuses on family/future generation motivational headlines and 'reasons for taking part' followed by the 'call to action' in the key mailings. A push-to-web approach is valuable for increasing online participation which is beneficial for survey data quality and cost reduction, although it is likely to reduce response rates. Multiple reminders made a significant impact on response rates, and an initial invitation letter followed by at least two reminders can be beneficial to boost response rates, but a fourth mailing may not be as effective as sending fewer mailings to more participants from underrepresented groups.

Households in more deprived areas were less likely to participate in our study. For GB studies we recommend stratifying addresses by region and IMD quintile and over-sampling from areas with low IMD quintile to combat response bias. The results are most relevant to GB smart meter studies since our response rates are influenced by the uneven rollout of SMETS2 smart meters which we know are less likely to have been installed in flats at the current time. We cannot say whether similar area-based affluence metrics in other countries would show similar results but we hypothesise that it is quite likely. 
We recommend that for a large-scale study, such as the planned $10,000+$ SERL sample, an initial recruitment drive which pilots and empirically tests study design options is useful to achieve an ultimately representative sample. A staged recruitment processes should then implement multiple waves in order to understand differential response rates and evolve the most cost-effective recruitment strategies. This also enables under-represented groups to be adaptively targeted to overcome low response rates and so reduce subsequent bias.

Our participant materials (invitation letters, accompanying information, survey and consent form) were designed with guidance from the experienced fieldwork agency Ipsos MORI and our university ethics board, and improved from cognitive testing with (smart meter owning) members of the public. Survey questions were devised and discussed by researchers from multiple universities and harmonised with national survey questions where possible. We invite researchers to use these resources (Appendix 10.2 and [54]) for their energy studies. This is particularly salient in light of the recent global COVID-19 lockdowns when face-to-face recruitment changed from expensive to impossible. With the future uncertain, it may be that our results and materials can offer guidance for other studies with the same aims.

\subsection{LIMITATIONS AND DIRECTIONS FOR FUTURE RESEARCH}

While this study makes an important contribution on the effects of recruitment strategies for energy studies, there are limitations to the potential conclusions.

First, this was a single experimental study in England and Wales in August-September 2019. We compared our results with those in a similar Australian study [18], but generalisations to other cultures and contexts should be cautious. Smart meter rollouts and governance of data ownership and access vary by country, as may consumer attitudes towards data sharing. Within GB the participants are not representative of the population. We were able to identify some types of sample bias from the survey, but full knowledge of sample bias is not possible. Recruitment strategies were assessed for their impact on sample bias and these will be considered for future recruitment for this project. Our analysis showed that over-sampling from lower IMD quintiles to overcome their lower response rates is likely to improve sample representativeness, and future SERL recruitment will aim to rebalance the representation across IMD quintiles. We recommend further research in other countries to test the utility of equivalent area-based metrics. In future work we will apply our results to the extension of SERL recruitment to the North of England and Scotland where response rates are currently untested in this setting.

Second, the greatest treatment impact came from using messaging content version 1 compared to version 2. Both the family-related messaging and its structure in the key mailings may have contributed to version 1's success, but it was not possible with this study design to determine their individual contributions. Separating structure from messaging could be trialled in future, as well as other types of messages. This can be difficult because it is best practice to use different messages and structures in each mailing.

Third, the two incentives were very specific, and others, such as unconditional monetary incentives were not tested due to their relative expense. Different monetary or unconditional incentives may also be effective. 


\section{CONCLUSIONS}

This study tested the effects of several recruitment strategies on participation rates and sample bias for a planned $10,000+$ sample of British smart metered households. Offering a conditional $f 5$ voucher increased participation and reduced sample bias whereas an unconditional thermometer did not. Family-oriented messaging in the key mailings with a 'reasons for participation' then 'call to action' structure was significantly more effective than other messaging and structures tested. A push-to-web approach decreased response but increased online response to a much greater extent, reducing processing costs and improving survey data fidelity. Multiple reminders increased response significantly, but while a fourth mailing (third reminder) marginally increased response it is unlikely to be cost-effective. Aiming for a GB IMD quintile-representative sample for future recruitment is a beneficial, easy-to-implement strategy that will reduce sample bias for key demographics such as dwelling type, size and financial well-being all of which are policy-relevant dimensions.

Our results and participant materials can benefit energy studies generally but especially those requiring consent to access energy data and can be used to inform future research into motivational strategies for energy study participation. UK-based researchers can apply to access the data collected by the SERL project which will increase from the 1711 pilot participants reported here to over 10,000 participants in 2021, collecting survey and half-hourly energy data until at least 2022 [16,55].

\section{ACKNOWLEDGEMENTS}

This work has been funded by EPSRC through grant EP/P032761/1. There are over 30 individuals across 8 organisations in the SERL Consortium (University College London, the University of Essex (UK Data Archive), University of Edinburgh, Cardiff University, Loughborough University, Leeds Beckett University, the University of Southampton and the Energy Saving Trust) who have contributed to the development of SERL and thus the content of this paper. Particular thanks go to the SERL technical team at the UK Data Archive: Darren Bell, Deirdre Lungley, Martin Randall and Jacob Joy and to James O'Toole at UCL. Ipsos MORI contributed to the research design and mailing development and carried out the fieldwork.

\section{AUTHOR CONTRIBUTIONS}

Ellen Webborn: Conceptualisation, methodology, software, validation, formal analysis, data curation, writing - original draft. Eoghan McKenna: conceptualisation, methodology, writing - review \& editing. Simon Elam: Conceptualisation, methodology, writing - review \& editing, supervision, funding acquisition. Ben Anderson: conceptualisation, validation, formal analysis, writing - review \& editing, supervision. Adam Cooper: conceptualisation, writing - review \& editing. Tadj Oreszczyn: funding acquisition, writing - review \& editing. 


\section{APPENDIX}

\subsection{LOGISTIC REGRESSION ANALYSIS}

Table 9: Statistical effect model controlling for IMD quintile and region. p-values < 0.05 highlighted in bold. Base cases: IMD quintile 3, South East, no incentive, no push-to-web, content version 2.

\begin{tabular}{|c|c|c|c|c|c|c|c|c|c|}
\hline Category Variable & $\begin{array}{l}\text { Coeff- } \\
\text { icient }\end{array}$ & $\begin{array}{r}\text { Coeff } \\
\text { (lower } \\
95 \%)\end{array}$ & $\begin{array}{r}\text { Coeff } \\
\text { (upper } \\
95 \% \text { ) }\end{array}$ & $\begin{array}{l}\text { Odds } \\
\text { Ratio }\end{array}$ & $\begin{array}{r}\text { OR } \\
\text { (lower } \\
95 \%)\end{array}$ & $\begin{array}{r}O R \\
\text { (upper } \\
95 \% \text { ) }\end{array}$ & $\begin{array}{r}\text { Standard } \\
\text { error }\end{array}$ & Z value & $\begin{array}{r}P- \\
\text { value }\end{array}$ \\
\hline Intercept & -2.464 & -2.647 & -2.284 & 0.085 & 0.071 & 0.102 & 0.093 & -26.560 & 0.000 \\
\hline IMD 1 & -0.336 & -0.523 & -0.151 & 0.715 & 0.593 & 0.860 & 0.095 & -3.545 & 0.000 \\
\hline IMD 2 & -0.166 & -0.330 & -0.002 & 0.847 & 0.719 & 0.998 & 0.083 & -1.986 & 0.047 \\
\hline IMD 4 & 0.303 & 0.154 & 0.453 & 1.354 & 1.167 & 1.573 & 0.076 & 3.978 & 0.000 \\
\hline IMD 5 & 0.420 & 0.271 & 0.570 & 1.522 & 1.311 & 1.769 & 0.076 & 5.501 & 0.000 \\
\hline Region East Midlands & -0.146 & -0.345 & 0.049 & 0.864 & 0.708 & 1.050 & 0.100 & -1.456 & 0.146 \\
\hline Region $\begin{array}{l}\text { East Of } \\
\text { England }\end{array}$ & 0.107 & -0.062 & 0.275 & 1.113 & 0.940 & 1.316 & 0.086 & 1.249 & 0.212 \\
\hline Region $\begin{array}{c}\text { Greater } \\
\text { London }\end{array}$ & -0.010 & -0.176 & 0.156 & 0.990 & 0.839 & 1.169 & 0.085 & -0.116 & 0.908 \\
\hline Region South West & 0.131 & -0.039 & 0.301 & 1.141 & 0.961 & 1.351 & 0.087 & 1.515 & 0.130 \\
\hline Region Wales & 0.277 & 0.081 & 0.470 & 1.319 & 1.084 & 1.600 & 0.099 & 2.793 & 0.005 \\
\hline $\begin{array}{ll}\text { Region } & \text { West } \\
\text { Midlands }\end{array}$ & -0.031 & -0.217 & 0.152 & 0.969 & 0.805 & 1.164 & 0.094 & -0.331 & 0.741 \\
\hline Incentive Thermometer & 0.066 & -0.058 & 0.190 & 1.068 & 0.943 & 1.210 & 0.063 & 1.042 & 0.298 \\
\hline Incentive Voucher & 0.137 & 0.014 & 0.260 & 1.147 & 1.014 & 1.296 & 0.063 & 2.186 & 0.029 \\
\hline $\begin{array}{l}\text { Push to } \\
\text { Web TRUE }\end{array}$ & -0.119 & -0.219 & -0.019 & 0.888 & 0.803 & 0.981 & 0.051 & -2.325 & 0.020 \\
\hline $\begin{array}{c}\text { Content } \\
\text { version }\end{array}$ & 0.147 & 0.047 & 0.248 & 1.159 & 1.048 & 1.281 & 0.051 & 2.883 & 0.004 \\
\hline
\end{tabular}

Table 10: Statistical effect model including interaction effects between IMD quintile and incentive and IMD quintile and push-to-web, controlling for IMD quintile and region. p-values < 0.05 are highlighted in bold. Base cases: IMD quintile 3, South East, no incentive, no push-to-web, content version 2. We do not find significant interactions at the $p=0.05$ level.

$\begin{array}{lrrrrrrrrr}\text { Variable } 1 & \text { Variable 2 } & \begin{array}{r}\text { Coeff- } \\ \text { icient }\end{array} & \begin{array}{r}\text { Coeff } \\ \text { (lower } \\ \text { 95\%) }\end{array} & \begin{array}{r}\text { Coeff } \\ \text { (upper } \\ 95 \%)\end{array} & \begin{array}{r}\text { Odds } \\ \text { Ratio }\end{array} & \begin{array}{r}\text { OR } \\ \text { (lower } \\ 95 \%)\end{array} & \begin{array}{r}\text { OR } \\ \text { (upper } \\ 95 \%)\end{array} & \begin{array}{r}\text { Standard } \\ \text { error }\end{array} & \begin{array}{r}\text { Z value } \\ \text { value }\end{array} \\ \text { Intercept } & -2.465 & -2.721 & -2.218 & 0.085 & 0.066 & 0.109 & 0.128 & -19.189 & \mathbf{0 . 0 0 0} \\ \text { IMD 1 } & -0.260 & -0.633 & 0.104 & 0.771 & 0.531 & 1.110 & 0.188 & -1.386 & 0.166 \\ \text { IMD 2 } & -0.207 & -0.541 & 0.126 & 0.813 & 0.582 & 1.134 & 0.170 & -1.215 & 0.224 \\ \text { IMD 4 } & 0.426 & 0.130 & 0.725 & 1.531 & 1.139 & 2.065 & 0.152 & 2.809 & 0.005 \\ \text { IMD 5 } & 0.284 & -0.021 & 0.591 & 1.328 & 0.980 & 1.806 & 0.156 & 1.823 & 0.068 \\ \text { East Midlands } & -0.146 & -0.345 & 0.049 & 0.864 & 0.708 & 1.050 & 0.100 & -1.456 & 0.145\end{array}$




\begin{tabular}{|c|c|c|c|c|c|c|c|c|c|c|}
\hline Variable 1 & Variable 2 & $\begin{array}{c}\text { Coeff- } \\
\text { icient }\end{array}$ & $\begin{array}{r}\text { Coeff } \\
\text { (lower } \\
95 \%)\end{array}$ & $\begin{array}{r}\text { Coeff } \\
\text { (upper } \\
95 \%)\end{array}$ & $\begin{array}{l}\text { Odds } \\
\text { Ratio }\end{array}$ & $\begin{array}{r}\text { OR } \\
\text { (lower } \\
95 \%)\end{array}$ & $\begin{array}{r}\text { OR } \\
\text { (upper } \\
95 \% \text { ) }\end{array}$ & $\begin{array}{r}\text { Standard } \\
\text { error }\end{array}$ & Z value & $\begin{array}{r}P- \\
\text { value }\end{array}$ \\
\hline $\begin{array}{l}\text { East Of } \\
\text { England }\end{array}$ & & 0.107 & -0.062 & 0.275 & 1.113 & 0.940 & 1.316 & 0.086 & 1.250 & 0.211 \\
\hline $\begin{array}{l}\text { Greater } \\
\text { London }\end{array}$ & & -0.010 & -0.176 & 0.156 & 0.990 & 0.839 & 1.169 & 0.085 & -0.114 & 0.910 \\
\hline South West & & 0.132 & -0.039 & 0.301 & 1.141 & 0.962 & 1.352 & 0.087 & 1.517 & 0.129 \\
\hline Wales & & 0.278 & 0.081 & 0.471 & 1.320 & 1.085 & 1.601 & 0.099 & 2.797 & 0.005 \\
\hline $\begin{array}{l}\text { West } \\
\text { Midlands }\end{array}$ & & -0.031 & -0.217 & 0.152 & 0.969 & 0.805 & 1.165 & 0.094 & -0.330 & 0.741 \\
\hline Thermometer & & 0.109 & -0.167 & 0.386 & 1.115 & 0.846 & 1.472 & 0.141 & 0.776 & 0.438 \\
\hline Voucher & & 0.198 & -0.073 & 0.471 & 1.219 & 0.930 & 1.601 & 0.138 & 1.431 & 0.152 \\
\hline Push to Web & & -0.195 & -0.417 & 0.026 & 0.823 & 0.659 & 1.027 & 0.113 & -1.722 & 0.085 \\
\hline version 1 & & 0.147 & 0.047 & 0.248 & 1.158 & 1.048 & 1.281 & 0.051 & 2.883 & 0.004 \\
\hline IMD 1 & $\begin{array}{l}\text { Thermo- } \\
\text { meter }\end{array}$ & -0.180 & -0.642 & 0.282 & 0.835 & 0.526 & 1.325 & 0.235 & -0.763 & 0.445 \\
\hline IMD 2 & $\begin{array}{l}\text { Thermo- } \\
\text { meter }\end{array}$ & -0.048 & -0.461 & 0.364 & 0.953 & 0.631 & 1.439 & 0.210 & -0.229 & 0.819 \\
\hline IMD 4 & $\begin{array}{l}\text { Thermo- } \\
\text { meter }\end{array}$ & -0.270 & -0.641 & 0.100 & 0.763 & 0.527 & 1.106 & 0.189 & -1.427 & 0.154 \\
\hline IMD 5 & $\begin{array}{l}\text { Thermo- } \\
\text { meter }\end{array}$ & 0.206 & -0.163 & 0.575 & 1.229 & 0.849 & 1.776 & 0.188 & 1.093 & 0.275 \\
\hline IMD 1 & Voucher & -0.068 & -0.514 & 0.379 & 0.934 & 0.598 & 1.461 & 0.228 & -0.298 & 0.766 \\
\hline IMD 2 & Voucher & 0.089 & -0.310 & 0.489 & 1.093 & 0.734 & 1.631 & 0.204 & 0.439 & 0.660 \\
\hline IMD 4 & Voucher & -0.244 & -0.608 & 0.119 & 0.783 & 0.544 & 1.127 & 0.185 & -1.315 & 0.189 \\
\hline IMD 5 & Voucher & -0.027 & -0.396 & 0.342 & 0.973 & 0.673 & 1.408 & 0.188 & -0.143 & 0.886 \\
\hline IMD 1 & $\begin{array}{l}\text { Push-to- } \\
\text { web }\end{array}$ & 0.015 & -0.355 & 0.383 & 1.015 & 0.701 & 1.467 & 0.188 & 0.078 & 0.938 \\
\hline IMD 2 & $\begin{array}{l}\text { Push-to- } \\
\text { web }\end{array}$ & 0.050 & -0.277 & 0.377 & 1.051 & 0.758 & 1.458 & 0.167 & 0.300 & 0.764 \\
\hline IMD 4 & $\begin{array}{l}\text { Push-to- } \\
\text { web }\end{array}$ & 0.105 & -0.194 & 0.404 & 1.111 & 0.824 & 1.498 & 0.152 & 0.686 & 0.492 \\
\hline IMD 5 & $\begin{array}{l}\text { Push-to- } \\
\text { web }\end{array}$ & 0.153 & -0.144 & 0.450 & 1.165 & 0.866 & 1.569 & 0.152 & 1.009 & 0.313 \\
\hline
\end{tabular}

\subsection{PARTICIPANT MATERIALS}

This section contains reproductions of the (2-page) invitation letter (test cell 1 ) and the (2-page) participant information sheet (provided in all mailings and online). 


\section{HELP TO MAKE OUR ENERGY FIT FOR FUTURE GENERATIONS}

Your address 1

Your address 2

Your address 3

Your address 4

Your Postcode

Dear Sir/Madam,

We are asking for around 10 minutes of your time to help with an important research study being funded by a research council. The study is being led by University College London (UCL), with six other UK universities and the Energy Saving Trust. Your address has been randomly selected from households with a smart meter.

Why should you take part?

By participating, you will help us gain a better understanding of energy usage in the UK. This will:

- $\quad$ help the UK to become more energy efficient

- help to protect the environment for your family and future generations

- help reduce future household energy bills

What would you need to do?

This is simple and easy and should take $\mathbf{1 0}$ minutes of your time. No one will need to visit your home or make any changes to your smart meter or energy supply. All we are asking you to do is:

\section{$\checkmark$ Provide your consent for UCL to access your smart meter data}

$\checkmark$ Answer a few questions about your household and energy usage

This can be done online:

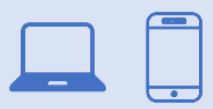

To participate, visit:

www.SERL.ac.uk/Portal

Enter your unique code:

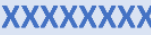

How will your data be used?

Your smart meter data will be shared with UCL for research purposes only. All data will be treated as strictly confidential, stored securely and managed in accordance with GDPR regulations.

Thank you very much for giving your time to help with this important study.

Yours faithfully,
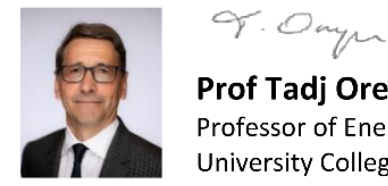

\section{Prof Tadj Oreszczyn}

Professor of Energy and Environment University College London
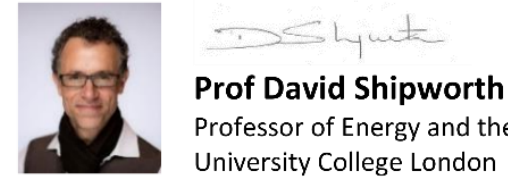

Professor of Energy and the Built Environment

University College London 


\section{Frequently asked questions}

Who can take part?

You must be aged 18 or over and regularly living at this address to take part. This invitation is for this address only and should not be passed to anyone not living at this address.

What will happen to me if I take part?

After completing the consent form and survey, UCL will start collecting data from your smart meter. We will do this remotely via the secure smart meter communication network. We won't need to visit your address at any stage and you won't need to do anything else. Your energy bills will not be affected in any way by our collection of your smart meter data.

What smart meter data will be shared with UCL, if I agree to take part?

- Half-hourly energy consumption readings (and readings for up to the past 12 months)

- Information about your energy tariff

What will be linked to my smart meter energy data?

We will link your survey responses and smart meter data. We may also seek to link information from other sources e.g. weather data for your local area, Energy Performance Certificate (if available), information from the Census about the area where you live etc. Any further data sources that we may want to link will be approved by an independent research ethics committee.

Will my data ever be sold or used for commercial purposes?

No, your data will never be sold and will only ever be used to conduct scientific research by approved researchers. No data will be shared with your energy supplier.

How do I receive the $₫ 5$ voucher?

Once you have completed the consent form and survey, we will send you a $f 5$ Love2Shop voucher that can be redeemed at over 100 retailers. If you complete online, we will request your email address and send you an e-voucher. If you complete by post, we will send you a physical voucher.

Who is running this project?

This is being led by University College London with the support of University of Essex (UK Data Archive), Cardiff University, University of Edinburgh, Leeds Beckett University, Loughborough University, University of Southampton and the Energy Saving Trust. Ipsos MORI, an independent research company, is supporting UCL with the study and is responsible for the mailings and the survey.

Do I have to take part?

It is your decision to participate and you can withdraw your consent at any time without giving a reason. Contact details are provided below.

How do I contact someone if I need help or have a query? Should you have any further questions or queries please consult the attached Information Sheet. If you still have any questions or need support at any stage, you can send an email to: helpdesk@serl.ac.uk or you can call the Freephone helpline <REDACTED>. Both of these services are managed by Ipsos MORI who are supporting UCL with the study.

$\begin{array}{ll}\text { For more information visit } & \text { www.SERL.ac.uk } \\ \text { Email } & \text { helpdesk@serl.ac.uk } \\ \text { Freephone helpline } & \text { <REDACTED> }\end{array}$




\section{Information Sheet - Smart Energy Research Lab}

Please read through the following information about the study prior to taking part. If you would like further information on any aspect of the study, please contact us using the contact details below.

What is the purpose of the project?

With rising energy prices, rapid social and technological change, and the threat of climate change, understanding our nation's energy needs has never been more important. Your participation will enable UK universities to carry out research to better understand how we use energy in our homes. The results will be used to inform effective government policies, drive technological innovation, and make energy consumption more secure, sustainable and affordable.

Who is the project run by?

The project is being led by University College London (UCL), in partnership with the University of Essex (UK Data Archive), Cardiff University, University of Edinburgh, Leeds Beckett University, Loughborough University, University of Southampton and the Energy Saving Trust, and funded by the Engineering and Physical Sciences Research Council. Ipsos MORI is supporting UCL with the study and is responsible for the mailings and survey. This study has been approved by the UCL Research Ethics Committee: ID - 14793/001.

Why have I been chosen?

We aim to have around 10,000 households taking part in the study from across Great Britain. Your address has been selected at random from households with a smart meter. Other than your address and basic information about the meter installation, no other data has been shared with UCL up until this point.

Do I have to take part?

You are not obliged to take part, but the success of the project depends on your participation. Should you choose to participate, you can withdraw at any time by logging on to the participant portal (www.SERL.ac.uk/portal), by e-mailing us at helpdesk@serl.ac.uk or by writing to Smart Energy Research Lab, 14 Upper Woburn Place, UCL, London WC1H ONN.

What will happen if I take part?

If you choose to take part, then you will need to provide consent for UCL to access your smart meter data and you will be asked to complete a short survey. This can be done either online or by post. If you would like to request postal versions of the consent and survey forms, please email or call the helpline to request these.

Once we receive your consent, we will then start accessing your smart meter(s) data. We will do this remotely without the need to visit your address and you will not need to do anything further. We will continue to collect your smart meter data until you withdraw from the project or move home. If you wish to continue participating after you have moved home, then please let us know by contacting us. Your data will be stored securely at the UK Data Archive and made accessible through a secure environment to accredited UK researchers on approved research projects. We will contact you once per year to remind you that we are accessing your smart meter data, notify you about how we are using your data in our research, describe our results, and remind you how you can withdraw from the project. We may also invite you to complete a follow-up survey.

What data will be accessed from my smart meter?

If you consent to participate, we will remotely access the following data from your smart meter(s):

- Half-hourly energy consumption readings (and any historic readings dating back 12 months, or less if you tell us you moved into your address less than 12 months ago)

- Information about your energy tariff

- Information about what devices are connected to your smart meter(s), such as an in-home display

The Smart Energy Code and how we collect your smart meter data UCL are an accredited Party to the Smart Energy Code (SEC), the UK legislation that governs access to smart meter data. CGI (an accredited SEC Party and DCC User) provide a technical service that connects to the national smart meter communication network (the DCC Gateway) which will remotely collect your smart meter data and securely transfer it to the UK Data Archive at Essex University (who are partners in this research project and manage your data for $\mathrm{UCL}$ ). 
How will my data be linked?

The value of the smart meter data greatly increases when data is linked (or combined) with other information.

We will link your survey responses and smart meter data with data about your local area and your property e.g. weather data or the Energy Performance Certificate for your property, if available. We may link your data to other sources that we can lawfully hold about your address for scientific research purposes in the public interest. Linking of data will only happen with the approval of an independent research ethics committee.

What are the possible benefits of taking part?

Energy research is important to inform effective government policies, drive technological innovation, and make energy consumption more secure, sustainable and affordable. You may benefit indirectly from these in the future. Taking part is intended to deliver benefits to society and to future generations.

Are there any possible disadvantages or risks of taking part?

This is an observational study only so there should be no risks or disadvantages to you.

Will my taking part in this project be kept confidential?

Your participation in the project will be kept strictly confidential. We commit to safeguarding your privacy and we will not share your data with any third parties other than accredited UK researchers working on approved research projects. Confidentiality will be respected subject to legal constraints and professional guidelines.

Will my data ever be sold or used for commercial purposes?

No, the data accessed for this study will not be sold and will only ever be used to conduct scientific research.

What will happen to the results of the research project?

We will publish the results of our research on our website and in a variety of publications such as academic books, journals, and at conferences. Individuals and households will not be identified in any publication.

Data Protection Privacy Notice

Information on your rights as a participant and how UCL uses participant information are available at: https://www.ucl.ac.uk/legal-services/privacy/ucl-general-research-participant-privacy-notice University College London (UCL) is the Data Controller for this project. UK Data Archive and Ipsos MORI are Data Processors. The UCL Data Protection Officer provides oversight of UCL activities involving the processing of personal data. If you are concerned about how your personal data is being processed, or if you would like to contact us about your rights, please contact UCL in the first instance at data-protection@ucl.ac.uk. The categories of personal data used will include: name, address, smart meter data, survey responses, and energy performance certificate data (where available). The lawful basis used to process this data is performance of a task in the public interest. In the survey, you may choose to tell us if anyone in your household is not working because of long-term sickness or disability. This is special category data and the lawful basis used to process this is scientific and historical research or statistical purposes. Your personal data will be processed as long as required for the research project. We will keep your data secure, store your contact details separately from data used for research, and minimise the processing of personal data wherever possible, in accordance with GDPR regulations.

What if something goes wrong?

If you wish to make a complaint you should inform us directly using the contact details provided. If you feel that your complaint has not been handled to your satisfaction you can contact the Chair of the UCL Research Ethics Committee - ethics@ucl.ac.uk. If you remain unsatisfied, you have the right to lodge a formal complaint with the UK Information Commissioner's Office (ICO). Full details may be accessed on the complaints section of the ICO's website: https://ico.org.uk/make-a-complaint/

Contact for further information

Email: helpdesk@serl.ac.uk

Website: www.serl.ac.uk

Address: Smart Energy Research Lab, 14 Upper Woburn Place, University College London, London WC1H ONN

Thank you for reading this information sheet. Please keep it for your records. 

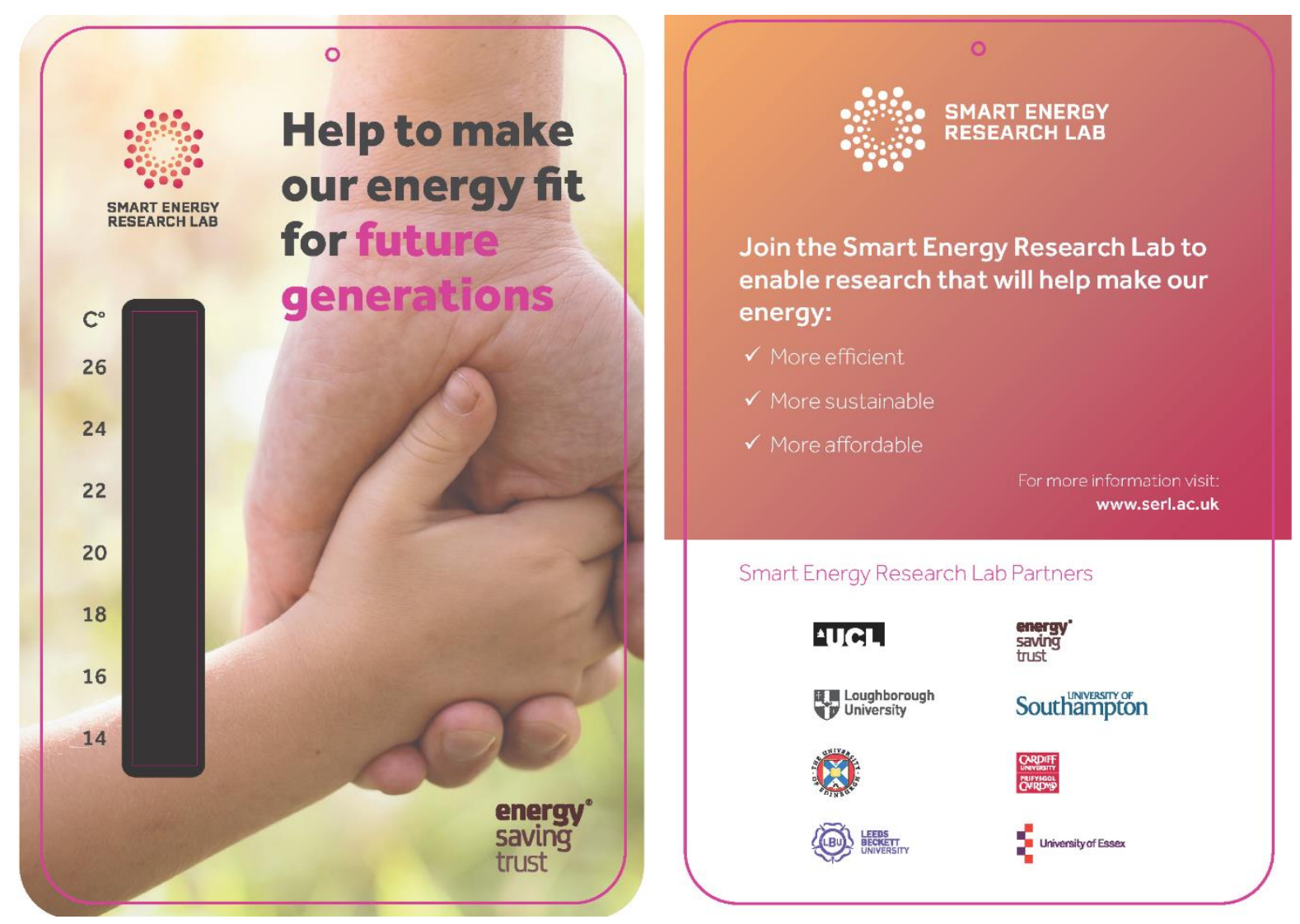

Figure 3: Front (left) and back (right) of the conditional incentive design; a room thermometer.

\section{REFERENCES}

[1] G. Strbac, Demand side management: Benefits and challenges, Energy Policy. 36 (2008) 4419-4426. https://doi.org/10.1016/j.enpol.2008.09.030.

[2] O. Golubchikov, K. O'Sullivan, Energy periphery: Uneven development and the precarious geographies of low-carbon transition, Energy Build. 211 (2020) 109818. https://doi.org/10.1016/j.enbuild.2020.109818.

[3] National Grid, System Operability Framework 2015, 2015.

[4] I. Hamilton, T. Oreszczyn, A. Summerfield, P. Steadman, S. Elam, A. Smith, Co-benefits of Energy and Buildings Data: The Case for supporting Data Access to Achieve a Sustainable Built Environment, Procedia Eng. 118 (2015) 958-968. https://doi.org/10.1016/j.proeng.2015.08.537.

[5] A.J. Summerfield, R. Lowe, Challenges and future directions for energy and buildings research, Build. Res. Inf. 40 (2012) 391-400. https://doi.org/10.1080/09613218.2012.693839.

[6] E. Webborn, T. Oreszczyn, Champion the energy data revolution, Nat. Energy. 4 (2019). https://doi.org/10.1038/s41560-019-0432-0.

[7] G. Walker, The dynamics of energy demand: Change, rhythm and synchronicity, Energy Res. Soc. Sci. 1 (2014) 49-55. https://doi.org/10.1016/j.erss.2014.03.012. 
[8] G. Strbac, I. Konstantelos, M. Pollitt, R. Green, Delivering future-proof energy infrastructure Report for, Natl. Infrastruct. Comm. (2016) 54.

[9] CCC, Net Zero: The UK's contribution to stopping global warming, Committe Clim. Chang. (2019) 275.

[10] E. Webborn, T. Oreszczyn, Champion the energy data revolution, Nat. Energy. 4 (2019) 624-626. https://doi.org/10.1038/s41560-019-0432-0.

[11] P. Grunewald, M. Diakonova, The electricity footprint of household activities implications for demand models, Energy Build. 174 (2018) 635-641. https://doi.org/10.1016/j.enbuild.2018.06.034.

[12] E.E. Ekanem, Y.Y. Shiu, Z. Tauanov, L. Sharma, J. V Henry, D. Das, G.T. Vladisavljevi, W.O. Pla, This item was submitted to Loughborough 's Institutional Repository ( https://dspace.lboro.ac.uk/) by the author and is made available under the following Creative Commons Licence conditions . For the full text of this licence, please go to : Developmen, (n.d.) 2-3.

[13] Department for Business Energy \& Industrial Strategy, Smart meters: a guide, (n.d.). https://www.gov.uk/guidance/smart-meters-how-they-work (accessed June 5, 2020).

[14] P. Sturgis, J. Williams, I. Brunton-Smith, J. Moore, Fieldwork effort, response rate, and the distribution of survey outcomes, Public Opin. Q. 81 (2017) 523-542. https://doi.org/10.1093/poq/nfw055.

[15] M.P. Battaglia, D.A. Dillman, M.R. Frankel, R. Harter, T.D. Buskirk, C.B. Mcphee, J.M. Dematteis, T. Yancey, Sampling, data collection, and weighting procedures for address-based sample surveys, J. Surv. Stat. Methodol. 4 (2016) 476-500. https://doi.org/10.1093/jssam/smw025.

[16] E. Webborn, S. Elam, E. McKenna, T. Oreszczyn, Utilising smart meter data for research and innovation in the UK, in: Proc. ECEEE 2019 Summer Study Energy Effic. ECEEE Belambra Presqu'île Giens, Fr., 2019: pp. 1387-1396. http://discovery.ucl.ac.uk/10075955/.

[17] R. V Jones, K.J. Lomas, Determinants of high electrical energy demand in UK homes: Appliance ownership and use, Energy Build. 117 (2016) 71-82. https://doi.org/10.1016/j.enbuild.2016.02.020.

[18] E.R. Frederiks, L.M. Romanach, A. Berry, P. Toscas, Making energy surveys more impactful: Testing material and non-monetary response strategies, Energy Res. Soc. Sci. 63 (2020) 101409. https://doi.org/10.1016/j.erss.2019.101409.

[19] B.K. Sovacool, J. Axsen, S. Sorrell, Promoting novelty, rigor, and style in energy social science: Towards codes of practice for appropriate methods and research design, Energy Res. Soc. Sci. 45 (2018) 12-42. https://doi.org/10.1016/j.erss.2018.07.007.

[20] B. Anderson, T. Rushby, A. Bahaj, P. James, Ensuring statistics have power: Guidance for designing, reporting and acting on electricity demand reduction and behaviour change programs, Energy Res. Soc. Sci. 59 (2020). https://doi.org/10.1016/j.erss.2019.101260.

[21] E.R. Frederiks, K. Stenner, E. V. Hobman, M. Fischle, Evaluating energy behavior change programs using randomized controlled trials: Best practice guidelines for policymakers, Energy Res. Soc. Sci. 22 (2016) 147-164. https://doi.org/10.1016/j.erss.2016.08.020. 
[22] G.B. Durrant, F. Steele, Multilevel modelling of refusal and non-contact in household surveys: Evidence from six UK Government surveys, J. R. Stat. Soc. Ser. A Stat. Soc. 172 (2009) 361-381. https://doi.org/10.1111/j.1467-985X.2008.00565.x.

[23] E. Sala, J. Burton, G. Knies, Correlates of Obtaining Informed Consent to Data Linkage: Respondent, Interview, and Interviewer Characteristics, Sociol. Methods Res. 41 (2012) 414-439. https://doi.org/10.1177/0049124112457330.

[24] E. Sala, G. Knies, J. Burton, Propensity to consent to data linkage: Experimental evidence on the role of three survey design features in a UK longitudinal panel, Int. J. Soc. Res. Methodol. 17 (2014) 455-473. https://doi.org/10.1080/13645579.2014.899101.

[25] Ofgem, Consumer views on sharing half-hourly settlement data, 2018. https://www.ofgem.gov.uk/publications-and-updates/consumer-research-datasets.

[26] W. Abrahamse, L. Steg, C. Vlek, T. Rothengatter, The effect of tailored information, goal setting, and tailored feedback on household energy use, energy-related behaviors, and behavioral antecedents, J. Environ. Psychol. 27 (2007) 265-276. https://doi.org/10.1016/j.jenvp.2007.08.002.

[27] R.M.J. Benders, R. Kok, H.C. Moll, G. Wiersma, K.J. Noorman, New approaches for household energy conservation-In search of personal household energy budgets and energy reduction options, Energy Policy. 34 (2006) 3612-3622. https://doi.org/10.1016/j.enpol.2005.08.005.

[28] M. Gleerup, A. Larsen, S. Leth-Petersen, M. Togeby, The Effect of Feedback by Text Message ( SMS ) and Email on Household Electricity Consumption: Experimental Evidence, Energy J. 31 (2018) 113-132.

[29] S. Schudy, V. Utikal, 'You must not know about me' - On the willingness to share personal data, J. Econ. Behav. Organ. 141 (2017) 1-13. https://doi.org/10.1016/j.jebo.2017.05.023.

[30] P.J. Edwards, I. Roberts, M.J. Clarke, C. DiGuiseppi, R. Wentz, I. Kwan, R. Cooper, L.M. Felix, S. Pratap, Methods to increase response to postal and electronic questionnaires, Cochrane Database Syst. Rev. (2009). https://doi.org/10.1002/14651858.MR000008.pub4.

[31] D. Bonino, L. De Russis, Design recommendations for smart energy monitoring: A case study in Italy, Energy Build. 91 (2015) 1-9. https://doi.org/10.1016/j.enbuild.2015.01.031.

[32] R.V. Andersen, J. Toftum, K.K. Andersen, B.W. Olesen, Survey of occupant behaviour and control of indoor environment in Danish dwellings, Energy Build. 41 (2009) 1116. https://doi.org/10.1016/j.enbuild.2008.07.004.

[33] K. Palmer, M. Walls, H. Gordon, T. Gerarden, Assessing the energy-efficiency information gap: Results from a survey of home energy auditors, Energy Effic. 6 (2013) 271-292. https://doi.org/10.1007/s12053-012-9178-2.

[34] S.Z. Attari, M.L. DeKay, C.I. Davidson, W.B. De Bruin, Public perceptions of energy consumption and savings, Proc. Natl. Acad. Sci. U. S. A. 107 (2010) 16054-16059. https://doi.org/10.1073/pnas.1001509107.

[35] C. Sansone, J.M. Harackiewicz, Intrinsic and extrinsic motivation: The search for optimal motivation and performance, 2000. 
[36] Y.I. Cho, T.P. Johnson, J.B. Vangeest, Enhancing Surveys of Health Care Professionals : A Meta-Analysis of Techniques to Improve Response, 36 (2013) 382-407. https://doi.org/10.1177/0163278713496425.

[37] M.C. David, R.S. Ware, Meta-analysis of randomized controlled trials supports the use of incentives for inducing response to electronic health surveys, J. Clin. Epidemiol. 67 (2014) 1210-1221. https://doi.org/10.1016/j.jclinepi.2014.08.001.

[38] K. Pforr, M. Blohm, A.G. Blom, B. Erdel, B. Felderer, M. Fräßdorf, K. Hajek, S. Helmschrott, C. Kleinert, U. Krieger, M. Kroh, S. Martin, D. Saßenroth, E. Trüdinger, B. Rammstedt, Are incentive effects on response rates and nonresponse bias in largescale, face-to-face surveys generalizable to Germany? Evidence from ten experiments, 79 (2015) 740-768. https://doi.org/10.1093/poq/nfv014.

[39] A.H. Church, Estimating the Effect of Incentives on Mail Survey Response Rates: A Meta-Analysis, Public Opin. Q. 57 (1993) 62. https://doi.org/10.1086/269355.

[40] K.D. Hopkins, A.R. Gullickson, Response rates in survey research: A meta-analysis of the effects of monetary gratuities, J. Exp. Educ. 61 (1992) 52-62. https://doi.org/10.1080/00220973.1992.9943849.

[41] C. Cook, F. Heath, R.L. Thompson, A meta-analysis of response rates in Web- or internet-based surveys, Educ. Psychol. Meas. 60 (2000) 821-836. https://doi.org/10.1177/00131640021970934.

[42] D.A. Dillman, J.D. Smyth, L.M. Christian, Internet, phone, mail, and mixed-mode surveys: the tailored design method, 4th ed., Hoboken: Wiley, 2014.

[43] F.J. Yammarino, S.J. Skinner, T.L. Childers, Understanding mail survey response behaviour A meta-analysis, Public Opin. Q. 55 (1991) 613-639. https://doi.org/10.1108/03090569810243776.

[44] R.J. Fox, M.R. Crask, J. Kim, Mail survey response rate: a meta-analysis of selected Techniques for inducing response, Public Opin. Q. 52 (1988) 467-491.

[45] I. Vassileva, E. Dahlquist, F. Wallin, J. Campillo, Energy consumption feedback devices' impact evaluation on domestic energy use, Appl. Energy. 106 (2013) 314-320. https://doi.org/10.1016/j.apenergy.2013.01.059.

[46] H. Carpenter, K.P. Uk, J. Burton, Adaptive push-to-web : experiments in a household panel study Non-technical summary, 2018.

[47] P. Bonnel, Postal, Telephone, and Face-to-Face Surveys: How Comparable are They?, in: Transp. Surv. Qual. Innov., Emerald Group Publishing Limited, 2003: pp. 215-237. https://doi.org/10.1108/9781786359551-012.

[48] B.L. Messer, D.A. Dillman, Surveying the General Public over the Internet Using Address-Based Sampling and Mail Contact Procedures, Public Opin. Q. 75 (2011) 429457. https://doi.org/https://doi.org/10.1093/poq/nfr021.

[49] B.M. Wells, T. Hughes, R. Park, CHIS Redesign Working Group, N. Ponce, Evaluating the California Health Interview Survey of the Future: Results from a Statewide Pilot of an Address-Based Sampling Mail Push-to-Web Data Collection, (2019).

[50] M.M. Millar, D.A. Dillman, Improving response to web and mixed-mode surveys, Public Opin. Q. 75 (2011) 249-269. https://doi.org/10.1093/poq/nfr003.

[51] A.W. Gouldner, The Norm of Reciprocity: A Preliminary Statement, Am. Sociol. Rev. 25 (1960) 161. https://doi.org/10.2307/2092623. 
[52] Highstreetvouchers.com, Love2shop Gift Vouchers, (n.d.). https://www.highstreetvouchers.com/gifts/love2shop-gift-vouchers (accessed June $5,2020)$.

[53] S. Elam, Smart Meter Data and Public Interest Issues - The National Perspective, 2016. file://C:/Users/Ellen Webborn/Documents/PapersInMendeley/teddinetpaper-simon-elam.pdf.

[54] S. Elam, E. Webborn, E. McKenna, T. Oreszczyn, B. Anderson, Ministry of Housing Communities \& Local Government, European Centre for Medium-Range Weather Forecasts, Royal Mail Group Limited, Smart Energy Research Lab Observatory Data, 2019-2020: Secure Access, (2020). https://doi.org/http://doi.org/10.5255/UKDA-SN8666-1.

[55] Smart Energy Research Lab, Welcome to the Smart Energy Research Lab, (n.d.). www.serl.ac.uk (accessed June 18, 2020).

[56] R Core Team, R: A Language and Environment for Statistical Computing, (2019). https://www.r-project.org/.

[57] D. Robinson, A. Hayes, S. Couch, broom: Convert Statistical Objects into Tidy Tibbles, (2021). https://cran.r-project.org/package=broom.

[58] J. Fox, S. Weisberg, An R Companion to Applied Regression, Third, Sage, Thousand Oaks (CA), 2019. https://socialsciences.mcmaster.ca/jfox/Books/Companion/.

[59] M. Dowle, A. Srinivasan, data.table: Extension of 'data.frame', (2019). https://cran.rproject.org/package=data.table.

[60] D. Gohel, flextable: Functions for Tabular Reporting, (2020). https://cran.rproject.org/package=flextable.

[61] H. Wickham, ggplot2: Elegant Graphics for Data Analysis, Springer-Verlag, New York, 2016. https://ggplot2.tidyverse.org.

[62] E. Neuwirth, RColorBrewer: ColorBrewer Palettes, (2014). https://cran.rproject.org/package $=$ RColorBrewer.

[63] H. Wickham, stringr: Simple, Consistent Wrappers for Common String Operations, (2019). https://cran.r-project.org/package=stringr. 